\title{
Assessment of knowledge, attitude, and practice of undergraduate medical students towards drug addiction and prevalence of drug addicts in Faculty of Medicine, University of Khartoum
}

Sara N. Bashir ( $\sim$ saranaiem97@gmail.com )

University of Khartoum

Elfatih A. Hasabo

University of Khartoum

Noha E. Elhag

University of Khartoum

Yousra S. Ahmed

University of Khartoum

Alaa T. Omer

University of Khartoum

Istabraq I. Abdelgadir

University of Khartoum

Heitham Awadalla

University of Khartoum

\section{Research Article}

Keywords: Drug addiction, Medical students, Knowledge, Attitude, Practice, Sudan

Posted Date: February 23rd, 2022

DOI: https://doi.org/10.21203/rs.3.rs-1374414/v1

License: (a) (i) This work is licensed under a Creative Commons Attribution 4.0 International License. Read Full License 


\section{Abstract}

Introduction: Addiction can be defined as the loss of control over drug use. Drug addiction makes major damage to the population and countries worldwide. Youths are a high-risk category for the use of the addicted substance. There are an increase in drugs usage and drinking alcohol in many developing countries. We conducted this study to assess knowledge, attitude, and practice towards drug addicts and addiction.

Methodology: A cross-sectional study was conducted in the Faculty of Medicine, the University of Khartoum between December 2020 and January 2021. 355 students participated in the study with a 97\% response rate. A structured questionnaire was used and data obtained were analyzed by chi-square test to identify any association between deferent variables.

Results: Among participants, $1.4 \%$ of students were reported they were addicted to drugs. $7.9 \%$ were tried at least one type of addicted illicit drug before. A very high percentage of students (92.1\%) were considered to have good knowledge about drug addiction. Only $32.1 \%$ had a positive attitude toward addicted patients and addiction and the majority had the opposite. Relatively low percent $(16.6 \%)$ have done a good practice toward addicted patients and drugs. There were significant associations between an academic year with all of the knowledge $(p=<0.001)$, attitude $(p=0.001)$, and practice $(p=<0.001)$ scores. Besides significant association between gender and practice $(p=0.004)$.

Conclusion: Although the prevalence of drug addiction among medical students was low, it is detected as a warrant red light. Knowledge of students about drug addiction is good but a negative attitude towards it has been notified. More attention is required towards students about drug addiction. Introduction of a course or workshop about the danger of drug addiction and how to deal with addicted patients.

\section{Background}

Addiction can be defined as "the loss of control over drug use, or the compulsive seeking and taking of drugs despite adverse consequences" (1). Globally, drug addiction makes major damage to the population and countries (2). There was a rapid increase in the prevalence of drug addiction worldwide (3), and this harmed individuals, families, communities, and society (4). Sadly, youths are a high-risk category for the use of addicted substances (5). Among youths, college students were mostly involved (5) because students usually experience independence from their parents, curiosity increases toward new experiences. Academic stressors that face students in this period of life (6) make a suitable situation for engagement in different activities, some are healthy but others are hazardous like smoking and drug abuse (7).

There are many types of addictive drugs such as cannabis, alcohol, opioids, antihistamines, amphetamines, cocaine, and others that were been used in different ratios (5). Alcohol is the most commonly used all over the world (8) while marijuana (cannabis) in the united states specifically (4). 
Results of prevention are almost modest. Treatment and prevention efforts are not fully effective in all individuals (4).

Due to rapid economic, social, and cultural transitions, records show a continuous increase in the usage of drugs and drinking alcohol in many developing countries and sub-Saharan Africa (9). African studies show that addictive drugs are common in secondary schools and some high educational levels (10). Sudan is not an exception from drug addiction (11).

In Sudan, drugs addiction is believed to be a growing problem affecting society (12). Although the consumption of alcohol has been prohibited by Sharia laws since 1983, is still illicitly used in many parts of the country (11). Since the country's rules are in an Islamic way, handling or consumption of such alcohol and illegal drugs are not allowed as so Islamic religion prohibits it (13). Unfortunately, an alarming pattern was noticed in the age group between 21 to 40 (14).

Increasing drug addicts especially among college students may have many different reasons. Some of the opinions mentioned by the students themselves are that different reasons were mentioned by students for the use of drugs as follow: to increase academic performance, to get personal pleasure, to get relief from tension, to stay awake, due to peer influence, due to academic dissatisfaction, to get acceptance by others, to be sociable to increase pleasure during sex, and due to religious practice (15).

About 19.7 million people aged 12 and more years old in the United States only were estimated to have a substance abuse disorder related to alcohol or illicit drug use in 2017 including 14.5 million (AUD) and 7.5 million people with an alcohol use disorder and an illicit drug use disorder respectively (4). This huge problem costs their nation more than $\$ 700$ billion annually due to crimes (16).

Only one out of six drug addicts had access to treatment services globally (14). Furthermore, in 2015 there were up to 33000 deaths because of opioids (17). In addition, addictive individuals are more likely to develop chronic pain, hypertension, injuries, poisoning, and overdose from these substances (18).

World drug report ranked Sudan as number 12 worldwide in terms of seized amounts of cannabis, with 17,255 kg seized in 2009 (19). In our country, we don't have enough information and statistics about the problem of addiction, which is a really big problem as if it is rise hence the high mortality attributed to this condition.

While illness, academic difficulties, risky behaviors, death, low productivity, and crime are all associated with drug addiction (5), substance use among college and university students remains an important area of research due to the implications of early substance dependence on the future of the youth. Such knowledge about it is essential to develop or adopt evidence-informed drug addiction-related health promotion and prevention interventions.

Even so, few studies had been conducted in this area of research in Sudan. This makes a knowledge gap about the extent of knowledge among youths particularly college students about drug addiction. Up to my knowledge, there is no published data conducted at the Faculty of Medicine, University of Khartoum 
about the aspect of drug addiction. In this study, we aimed to assess the level of knowledge, attitude, and practice of medical students towards drug addicts and addiction, and to identify the prevalence of drug addiction among medical students at the Faculty of Medicine, University of Khartoum.

\section{Methods}

\section{Study design and settings:}

This study is an observational descriptive cross-sectional study conducted among undergraduate medical students in six batches of Faculty of Medicine, University of Khartoum, Khartoum State, Sudan in the period from 28th of December 2020 to 23rd of January 2021.

The faculty of medicine located at Al-Qasr avenue in Khartoum state has around 2300 undergraduate medical students who graduate after completing six years curriculum. The curriculum is composed of three years of basic clinical sciences followed by three years of clinical sciences. Each year is composed of two semesters. The faculty was founded in 1924 and has graduated more than 90 batches.

\section{Participants:}

This study included all undergraduate medical students of both sexes older than 18 years studying at the Faculty of Medicine, University of Khartoum. All undergraduate medical students who refused to participate were excluded from the study.

\section{Instruments used to measure the variables of interest in the study:}

The data was collected using an online google form. A self-structured questionnaire containing 25 closeended questions adopted from relevant studies (2)(8)(14)(20) in the English language that takes about 4-5 minutes to complete was used to fulfill the objectives of the study (Appendix 1).

The questionnaire was divided into four sections:

Section 1: contain five questions regarding sociodemographic data including gender, age, academic year, marital status, and living condition.

Section 2: contain seven questions regarding knowledge about drug addiction which were the definition of addiction, source of knowledge, kind of illegal drugs, causing death, causing harm, causing a psychiatric problem, and treatability.

Section 3: contain seven questions regarding attitude towards drug addiction which were society forgiveness, criminality, avoidance, fair chance, causing the problem in Sudan, scaring, and tending to get sympathy. 
Section 4: contain six questions regarding practice in the drug addiction field which were: prevalence of addiction, reading about addiction, seeing addicted patient, participating in treatment, and giving advice to an addicted patient.

The questionnaire used was structured upon published literature and had no definitive standard or validated score. Therefore, suitable scores were used to have a better assessment of overall knowledge, attitude, and practice towards drug addiction. The knowledge score consists of 14 statements every single right answer took one point, and it was categorized into based poor knowledge (0-6) and good knowledge (7-14). The attitude score consists of eight statements each one right answer took one point, and it was categorized as negative attitude ( $0-4)$ and positive attitude (5-8). The practice score consists of 4 statements each one right answer took one point, and it was categorized as poor practice (0-2) and good practice (3-4).

\section{Data collection and Sampling:}

Stratified random sampling was conducted to acquire the responses from the participants via online distribution of google form during the study period. First, students were divided into six clusters according to their year of study. Then simple random sampling was used in each year of study according to the students' names listed in their respective batches using a random number generator called research randomizer. Distribution of the google form was done using social media such as WhatsApp and Telegram.

The total sample size was divided equally between selected batches in which 61 participants were taken from each batch. The purpose of the study was explained to each student, and those students who agreed to participate in the study were included. 355 students out of 366 were finally included in the study giving us a response rate of $97 \%$.

\section{Sample size calculation:}

To calculate the sample size the following equation was used $\mathrm{n}=\mathrm{N} \backslash\left(1+\mathrm{N}(e)^{2}\right)$. With population size 1989 and 0.05 margin of error, a sample of 333 can be considered as a minimal sample to represent the population. By adding $10 \%$ of the sample size, the sample size reached 366 .

\section{Statistical analysis:}

Initially, the data collected as a google form were organized into an excel spreadsheet. The data is then transferred and analyzed using Statistical Package for Social Sciences (SPSS) version 26. The data analysis was cleaned and analyzed. Descriptive statistics and summary measures, data display in tables. Both descriptive and inferential statistics involving. A Chi-square test was used to find associated factors. A p-value of less than 0.05 was considered statistically significant.

\section{Results}

\section{Participants' information}


Of all 355 participants, 246 (69.3\%) were females. The mean age of the participants (standard deviation) is 21.83 (2.053) ranging between the minimum of 18 and a maximum of 34 years. $346(97.5 \%)$ were unmarried and 355 (77.7\%) live with family and 72 (20.3\%) live in dorms. Second-year students, third-year and sixth-year students participated in equal percent $(n=61,(17.2 \%)$ for each), while the first-year expressed the least (15.5\%). Others baseline characteristics for the included medical students were shown in (Table 1$)$. 
Table 1

Baseline characteristics, knowledge, attitude, and practice of addiction among participants. $(n=35)$

\begin{tabular}{|ll|}
\hline Variables & $\mathrm{N}=355^{1}$ \\
\hline Age, years & $21.8 \pm 2.1$ \\
\hline Gender & \\
\hline Female & $246(69.3 \%)$ \\
\hline Male & $109(30.7 \%)$ \\
\hline Academic year & \\
\hline Fifth & $60(16.9 \%)$ \\
\hline First & $55(15.5 \%)$ \\
\hline Fourth & $57(16.1 \%)$ \\
\hline Second & $61(17.2 \%)$ \\
\hline Sixth & $61(17.2 \%)$ \\
\hline Third & $61(17.2 \%)$ \\
\hline Marital status & \\
\hline Married & $92(2.5 \%)$ \\
\hline Single & $346(97.5 \%)$ \\
\hline Living condition & \\
\hline In dorms & $72(20.3 \%)$ \\
\hline With family & $276(77.7 \%)$ \\
\hline With friend & $1(0.3 \%)$ \\
\hline With relatives & \\
\hline Knowledge score level & \\
\hline Good knowledge & $327(92.1 \%)$ \\
\hline Poor knowledge & \\
\hline Attitude score level & \\
\hline Good attitude & \\
\hline Poor attitude & \\
\hline Practice score level & \\
\hline
\end{tabular}




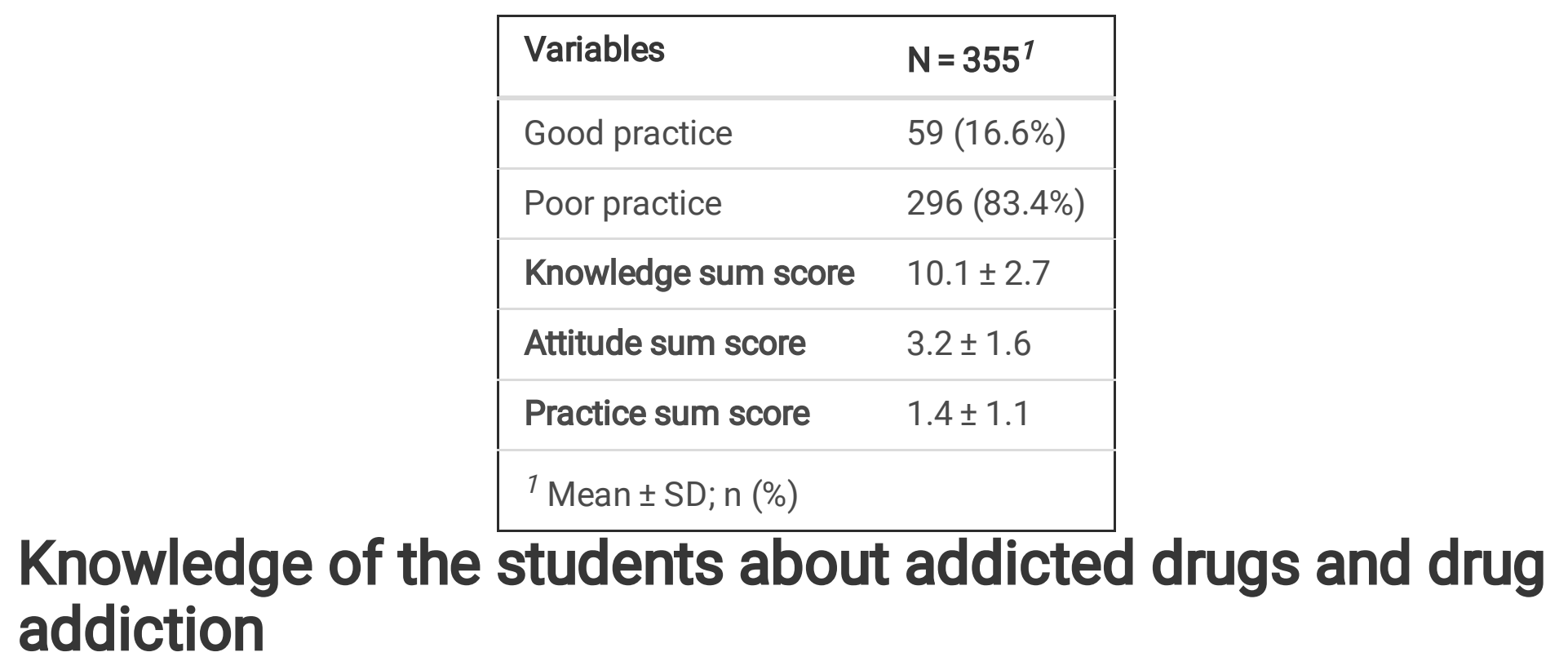

$327(92.1 \%)$ of the students were considered to have good knowledge about drug addiction with the sum of $10.1 \pm 2.7$ (Table 1). Alcohol was reported to be known in $16.3 \%$ of participants followed by cocaine, while $5 \%$ of participants knew pregabalin. $79.4 \%$ of students know the right definition of drug addiction. Half of them gain their knowledge from social media. $92.4 \%$ reported that drug addiction can lead to death. $92.7 \%$ think drug addiction is treatable. More details about the knowledge of participants were in Table 2. 
Table 2

Knowledge about addicted drugs and drug addiction among participants. $(n=355)$

\section{Variables}

$\mathrm{N}=355^{1}$

Did you know the following addicted drugs? (Yes)

Alcohol

Cannabis (hashish)

Cocaine

Amphetamine

Heroin

Cough syrup or DM

Tramadol

Pregabalin

54

Antihistamines

Do not hear about any

\section{Definition of addiction}

Do not know

Using an illegal drug at least one time

A chronic, relapsing disorder characterized by compulsive drug seeking, continued use despite harmful consequences

Continue to take a specific substance for more than 6 months without causing any harm

\section{Source of knowledge}

Books or lectures

Different sources 


\begin{tabular}{|c|c|}
\hline Variables & $N=355^{1}$ \\
\hline Friends & $\begin{array}{l}34 \\
(9.6 \%)\end{array}$ \\
\hline I don't hear about it ever & $\begin{array}{l}15 \\
(4.2 \%)\end{array}$ \\
\hline Relatives & $\begin{array}{l}48 \\
(13.5 \%)\end{array}$ \\
\hline Social media & $\begin{array}{l}177 \\
(49.9 \%)\end{array}$ \\
\hline TV & $\begin{array}{l}12 \\
(3.4 \%)\end{array}$ \\
\hline \multicolumn{2}{|l|}{ Addiction cause death } \\
\hline No, or do not know & $\begin{array}{l}27 \\
(7.6 \%)\end{array}$ \\
\hline Yes & $\begin{array}{l}328 \\
(92.4 \%)\end{array}$ \\
\hline \multicolumn{2}{|c|}{ Drug addiction is harmful to the body } \\
\hline No, or do not know & $\begin{array}{l}15 \\
(4.2 \%)\end{array}$ \\
\hline Yes & $\begin{array}{l}340 \\
(95.8 \%)\end{array}$ \\
\hline \multicolumn{2}{|c|}{ Drug addiction causes psychiatric problems } \\
\hline No, or do not know & $\begin{array}{l}12 \\
(3.4 \%)\end{array}$ \\
\hline Yes & $\begin{array}{l}343 \\
(96.6 \%)\end{array}$ \\
\hline \multicolumn{2}{|l|}{ Drug addiction is treatable } \\
\hline No, or do not know & $\begin{array}{l}26 \\
(7.3 \%)\end{array}$ \\
\hline Yes & $\begin{array}{l}329 \\
(92.7 \%)\end{array}$ \\
\hline${ }^{1} \mathrm{n}(\%)$ & \\
\hline
\end{tabular}

\section{Attitudes of students towards addicted patients and drug addiction:}


Of all participants, 273 (76.9\%) have negative (poor) attitudes towards drug addiction with the sum of $3.2 \pm 1.6$ (Table 1). Of all, 81 (22.8\%) of the participants see that drug addicts are more criminal than victims. $280(78.9 \%)$ of the participants believe that drug addiction is a problem to us here in Sudan, whereas $20(5.6 \%)$ see that it is not. More details about the attitudes of medical students were shown in Table 3.

Table 3

Attitudes towards addicted patients and drug addiction among participants. $(n=355)$

\begin{tabular}{|llll|}
\hline Questions & $\begin{array}{l}\text { Agree } \\
(\%)\end{array}$ & $\begin{array}{l}\text { Neutral } \\
(\%)\end{array}$ & $\begin{array}{l}\text { Disagree } \\
\text { (\%) }\end{array}$ \\
\hline Our society is too forgiving toward drug user & $73(20.6)$ & $118(33.2)$ & $164(46.2)$ \\
\hline Drug addict more as criminal than the victim & $81(22.8)$ & $161(45.4)$ & $113(31.8)$ \\
\hline Tend to avoid someone who is a drug addict & $\begin{array}{l}182 \\
(51.3)\end{array}$ & $129(36.3)$ & $44(12.4)$ \\
\hline $\begin{array}{l}\text { Drug addicts are not given a fair chance to get along in } \\
\text { society }\end{array}$ & $\begin{array}{l}144 \\
(40.6)\end{array}$ & $151(42.5)$ & $60(16.9)$ \\
\hline Addicted drugs are not a problem to us here in Sudan & $20(5.6)$ & $55(15.5)$ & $280(78.9)$ \\
\hline Drug addict scares you & $\begin{array}{l}188 \\
(53.0)\end{array}$ & $123(34.6)$ & $44(12.4)$ \\
\hline $\begin{array}{l}\text { Many drug addicts exaggerate their troubles to get } \\
\text { sympathy }\end{array}$ & $\begin{array}{l}106 \\
(29.9)\end{array}$ & $173(48.7)$ & $76(21.4)$ \\
\hline
\end{tabular}

The practice of students towards addicted patients and drug addiction:

Of all participants, 59 (16.6\%) have good practice with a sum of $1.4 \pm 1.1$ (Table 1). 218 out of 355 students $(61.4 \%)$ read about drugs addiction but only 12 students (3.4\%) participated in the treatment of addicted patients before. Moreover, 129 (36.3\%) participants advise the addicted patients. More details about the practice were shown in Table 4. 
Table 4

Practice toward addicted patients and drug addiction among participants. $(n=355)$

\begin{tabular}{|ll|}
\hline Variables & $\mathbf{N}=\mathbf{3 5 5}^{\mathbf{1}}$ \\
\hline \multicolumn{2}{|l|}{ The practice of students towards addicted patients and drug addiction } \\
\hline Tried illegal drug (Yes) & $28(7.9 \%)$ \\
\hline Addicted to a drug (Yes) & $5(1.4 \%)$ \\
\hline Read about drugs addiction (Yes) & $218(61.4 \%)$ \\
\hline See addicted patients (Yes) & $125(35.2 \%)$ \\
\hline Participated in treatment (Yes) & $12(3.4 \%)$ \\
\hline Advised an addict (Yes) & $129(36.3 \%)$ \\
\hline${ }^{1} \mathrm{n}(\%)$ & \\
\hline
\end{tabular}

\section{Prevalence of illicit drug use:}

Out of 355 students, $5(1.4 \%)$ were reported as addicted to one or more drugs whereas $28(7.9 \%)$ said they tried an addicted illicit drug at least one time before.

\section{Association between KAP scores and sociodemographic variables:}

Using cross-tabulation and Chi-square test, the association between knowledge, attitude, and practice with gender, age, academic year, marital status, and living condition were all studied. There was a significant association between gender and practice score $(p=0.044)$. Also, between academic year and with knowledge $(p=<0.001)$, attitude $(p=0.001)$ and practice scores $(p=<0.001)$ (Table 5). 
Table 5

Association of knowledge, attitude, and practice of drug addiction with baseline variables.

\begin{tabular}{|c|c|c|c|c|c|c|c|c|c|}
\hline \multirow[t]{2}{*}{ Variables } & \multicolumn{2}{|c|}{ Knowledge } & \multirow{2}{*}{$\begin{array}{l}\mathrm{p}- \\
\text { value }\end{array}$} & \multicolumn{2}{|l|}{ Attitude } & \multirow{2}{*}{$\begin{array}{l}\mathrm{p}- \\
\text { value }\end{array}$} & \multicolumn{2}{|c|}{ Practice } & \multirow{2}{*}{$\begin{array}{l}\mathrm{p}- \\
\text { value }\end{array}$} \\
\hline & Good & Poor & & Positive & Negative & & Good & Poor & \\
\hline Age & 88 & 18 & \multirow[t]{5}{*}{0.001} & 11 & 95 & \multirow[t]{5}{*}{0.002} & 7 & 99 & \multirow[t]{5}{*}{0.001} \\
\hline $18-20$ & 166 & 7 & & 46 & 127 & & 30 & 143 & \\
\hline $21-23$ & 68 & 3 & & 23 & 48 & & 21 & 50 & \\
\hline $24-26$ & 5 & 0 & & 2 & 3 & & 1 & 4 & \\
\hline \multicolumn{7}{|l|}{27 and more } & & & \\
\hline Gender & 105 & 4 & \multirow[t]{3}{*}{0.055} & 31 & 78 & \multirow[t]{3}{*}{0.133} & 25 & 84 & \multirow[t]{3}{*}{0.044} \\
\hline Male & 222 & 24 & & 51 & 195 & & 34 & 212 & \\
\hline \multicolumn{7}{|l|}{ Female } & & & \\
\hline Academic year & 43 & 12 & \multirow{7}{*}{ <.001 } & 4 & 51 & \multirow[t]{7}{*}{0.001} & 2 & 53 & \multirow{7}{*}{$\begin{array}{l}< \\
0.001\end{array}$} \\
\hline 1 st year & 53 & 8 & & 9 & 52 & & 1 & 60 & \\
\hline 2nd year & 59 & 2 & & 11 & 50 & & 8 & 53 & \\
\hline 3rd year & 56 & 1 & & 20 & 37 & & 2 & 55 & \\
\hline 4 th year & 58 & 2 & & 19 & 41 & & 27 & 33 & \\
\hline 5th year & 58 & 3 & & 19 & 42 & & 19 & 42 & \\
\hline \multicolumn{7}{|l|}{ 6th year } & & & \\
\hline Marital status & 320 & 7 & 0.153 & 80 & 266 & 1.000 & 57 & 289 & 0.648 \\
\hline Unmarried & 7 & 2 & & 2 & 7 & & 2 & 7 & \\
\hline \multicolumn{10}{|l|}{ Married } \\
\hline \multirow{2}{*}{$\begin{array}{l}\text { Living } \\
\text { condition }\end{array}$} & 259 & 17 & \multirow[t]{5}{*}{0.143} & 64 & 212 & \multirow[t]{5}{*}{0.273} & 40 & 236 & \multirow[t]{5}{*}{0.064} \\
\hline & 5 & 1 & & 2 & 4 & & 0 & 6 & \\
\hline WIth tamily & 62 & 10 & & 15 & 57 & & 19 & 53 & \\
\hline In dorms & 1 & 0 & & 1 & 0 & & 0 & 1 & \\
\hline With friend & & & & & & & & & \\
\hline
\end{tabular}

\section{Association between using addicted drugs and sociodemographic data:}


Using cross-tabulation and Chi-square test, an association between trying an addicted drug for at least one time and being addicted to any kind of drugs, with gender, age, academic year, marital status, and living condition was done. There were significant associations between trying an illegal drug before with both gender $(p=<0.001)$ and living conditions $(p=<0.001)$ (Table 6$)$. 
Table 6

Association of trying illegal drugs and addiction to drugs with baseline variables.

\begin{tabular}{|c|c|c|c|c|c|c|}
\hline \multirow[t]{2}{*}{ Variables } & \multicolumn{2}{|c|}{ Tried illegal drugs before } & \multirow[t]{2}{*}{ p-value ${ }^{*}$} & \multicolumn{2}{|c|}{ Addicted to a drug } & \multirow[t]{2}{*}{ P-value* } \\
\hline & yes & no & & yes & no & \\
\hline Age & 9 & 97 & 0.357 & 3 & 103 & 0.480 \\
\hline $18-20$ & 10 & 163 & & 1 & 172 & \\
\hline $21-23$ & 8 & 63 & & 1 & 70 & \\
\hline $24-26$ & 1 & 4 & & 0 & 5 & \\
\hline \multicolumn{7}{|l|}{27 and more } \\
\hline Gender & 21 & 88 & $<0.001$ & 2 & 107 & 0.645 \\
\hline Male & 7 & 239 & & 3 & 243 & \\
\hline \multicolumn{7}{|l|}{ female } \\
\hline Academic year & 3 & 52 & 0.639 & 2 & 53 & 0.589 \\
\hline 1 st year & 6 & 55 & & 1 & 60 & \\
\hline 2nd year & 6 & 55 & & 0 & 61 & \\
\hline 3 rd year & 3 & 54 & & 0 & 57 & \\
\hline 4 th year & 3 & 57 & & 1 & 59 & \\
\hline 5th year & 7 & 54 & & 1 & 60 & \\
\hline \multicolumn{7}{|l|}{6 th year } \\
\hline Marital status & 27 & 319 & 0.527 & 4 & 342 & 0.121 \\
\hline Unmarried & 1 & 8 & & 1 & 8 & \\
\hline \multicolumn{7}{|l|}{ Married } \\
\hline Living condition & 15 & 261 & $<0.001$ & 4 & 272 & 0.991 \\
\hline With family & 2 & 4 & & 0 & 6 & \\
\hline With relatives & 10 & 62 & & 1 & 71 & \\
\hline In dorms & 1 & 0 & & 0 & 1 & \\
\hline With friend & & & & & & \\
\hline
\end{tabular}

\section{Discussion}


The present study was an institutional descriptive cross-sectional study conducted on 255 students, enrolled to assess knowledge, attitude, and practice of drug addiction and prevalence of drug addiction among the medical students at the University of Khartoum.

266 students were approached in this study. However, 255 participants took part in the study resulting in a $97 \%$ response rate. This is approximately resembling the response rate of Ethiopian study on the students, where the response rate was $98.3 \%$ (15). Yet, this response is significantly high when compared to other studies conducted in Malaysia and New Zealand (2)(21).

The age of participants ranged from 18 to 34 years, in which the mean age $( \pm$ SD) was $21.83( \pm 2.053)$ which is considered as the young active age. Nearly two-thirds of participants were females who accounted for $(69.3 \%)$ while males accounted for only less than a third of students $(30.7 \%)$. This is reflecting the real majority of females in the faculty of medicine, at the University of Khartoum in which the males are approximately the third in the batch. Regarding their academic year, approximately from the six academic years were participated in the same proportion in the study, in which second-, third- and sixth-year students participate a little bit more than the other academic years. The majority of participating students were single (unmarried) and only a very small percent $(1.5 \%)$ of participants were married. Regarding the living condition, a considerable percentage of participants were lived with their family account for $(77.7 \%)$, followed by $(20.3 \%)$ in dorms, and the least proportions were $1.7 \%$ and $0.3 \%$ lived with relatives and with friends, respectively.

Regarding the knowledge about drug addiction, most of the students were familiar with most types of addictive drugs. Alcohol was found to be the most kind knew followed by cocaine, then heroin, then tramadol, then cannabis. Less than half of participants reported to know cough syrup, and less for amphetamine, then antihistamines, and lastly only one-fourth knew pregabalin. Alcohol is familiar long centuries ago in Sudan and it is a part of the culture in some areas as so it is the most familiar kind between students. This is different from another study in which heroine is the most familiar addicted drug (2).

Of the 355 students, the most were considered to have good knowledge about drug addiction which were $92.1 \%$. This is not surprising results as it is conducted in medical students. This is nearly resemble other studies conducted on students(2)(21). Although only $32.1 \%$ had a positive attitude toward addicted patients and addiction. This was the opposite of what was found among students in Malaysia and this may be affected by predominant social opinions in the aspects of drug addiction (2). $16.6 \%$ have done a good practice toward addicted drugs.

The prevalence of using addicted drugs among medical students in this study was found to be $1.4 \%$. This is a very low percent when compared with other studies conducted among college students in which it is $28 \%$ in Iran (8), $5.1 \%$ in Isfahan (3), This might be attributed to the stigma associated with this question and to the small proportion of males in this study where the drug addiction is more common among them, in addition to culture and religion of the region and the selected faculty in which conduct the research, in which the medical students are more aware of the danger and complications may be 
associated with drug addiction. While the prevalence of alcohol use itself was found to be $51.9 \%$ in Kenya (10). That is because of the availability of addictive drugs and specifically alcohol there while it is not widely available here in Sudan.

There was $7.9 \%$ of participants tried a kind of addictive drug at least one time before. This is considered a very low percent when compared with other percentages among university students which is $69.8 \%$ reported in Kenya (10) and 62.4\% in Ethiopia (15). This might be because addicted drugs are socially unacceptable and Haram in Islam religion so the adults do not even try any of it except small proportion like this. Association was found between illicit drug use and gender and with the living condition. Association with gender was found in previous studies in which significant association among adult urban population in Iran between being male and lifetime alcohol use was found with male to female ratio of 2.07 (8). Also, a strong association was found between gender and substance abuse with (AOR $(95 \% \mathrm{Cl}), 3.11(2.20,4.39))$ among university students in Ethiopia (15).

Regarding knowledge, attitude and practice there was a significant association with all of them and academic year, and all of them with age. This may clarify the role of the course of psychiatry taken in the fourth year. Also, there was a significant association between practice and gender. There was no association between gender and attitude as found in a study before (8) and with knowledge as in (2). No other statistically significant association was found regarding the scores and sociodemographic.

As far as we know, this is the first study to assess knowledge, attitude, and practice about drug addicts and addiction done in Sudan, particularly in the most active part of the community which is the adults specifically university students.

Difficulty in reaching the targeted students because of the lockdown due to COVID 19 second wave and limited time and number of data collectors was considered as limitations in this study.

\section{Conclusion}

The majority of the students had good knowledge about drug addiction although only less than the half of participants had a positive attitude towards drug addicts and three-quarters had poor practice towards addicted patients. Significant associations were determined between the knowledge with age and academic year of study. Also, associations between attitude and both gender and age were found positive. Moreover, practice is significantly associated with gender, age, and academic year of study. Finally, there is a significant association between trying an illegal drug before with both gender and living conditions.

\section{Declarations}

Ethical approval and consent to participate: Ethical approval of the study was obtained from the Technical and Ethical Review Board in the Department of Community Medicine, Faculty of Medicine, University of Khartoum, Khartoum, Sudan, and the national health research ethics committee, Federal 
Ministry of Health, Sudan. Informed consent was taken from all participants. All the study methodology was carried out following the relevant ethical guidelines and regulations.

Consent for publication: Not available.

Availability of data and materials: The datasets used and $\backslash$ or analyzed during the current study are available from the corresponding author on reasonable request.

Competing interest: The authors declare that they have no competing interests.

Funding: This study received no funding.

Authors' contributions: SNB: Project administration, study and questionnaire design, data collection, data analysis and interpretation, writing manuscript, and drafting the article. EAH: analysis plan, data analysis and interpretation, writing manuscript, and drafting the article. NEE, YSA, ATO, IIA: manuscript writing and editing. HA: Supervision. All authors revised the manuscript and approved it for publication.

Acknowledgments: The authors would like to thank the research agency: "Sudan Analytics for Research and Statistics" (Links: https://www.facebook.com/Sudan.Analytics/, https://www.linkedin.com/company/76092484/, https://twitter.com/Sudananalytics, https://telegram.me/Sudananalytics) for their help in our research.

\section{Additional files:}

1. Appendix 1 (Docx): includes the questionnaire.

\section{References}

1. J.Nestler E. Molecular Basis of Long-term Plasticity Underlying Addiction. Vol. 2. Macmillan Magazines Ltd; 2001. $10 \mathrm{p}$.

2. Nasir BM, Fuad MDF, Ghazi HF, Abdalqader MA. Knowledge, Attitudes, and Beliefs Related To Drugs among Pahang Matriculation Students in Malaysia. Int J Public Heal Res. 2016;(September).

3. Bashardoost N, Tirani M. Prevalence of addiction in males: Isfahan 2003. ARYA J. 2005;1(2):20035.

4. Uhl GR, Koob GF, Cable J. The neurobiology of addiction. Ann N Y Acad Sci. 2019;1451(1):5-28.

5. European Scientific Institute. AB, Abiodun OA, Sajo S. Alcohol and psychoactive substance use among medical students of the University of Ilorin, Nigeria. Eur Sci Journal, ESJ [Internet]. 2014;10(8):69-83. Available from: https://eujournal.org/index.php/esj/article/view/3008

6. Newcomb MD, Maddahian E, Bentler PM. Risk factors for drug use among adolescents: Concurrent and longitudinal analyses. Am J Public Health. 1986;76(5):525-31.

7. Garman JF, Hayduk DM, Crider DA, Hodel MM. Occurrence of exercise dependence in a college-aged population. J Am Coll Heal. 2004;52(5):221-8. 
8. Mehrabi M, Hajebi A, Mohebbi E, Baneshi MR, Khodadost M, Haghdoost AA, et al. Prevalence and Correlates of Lifetime Alcohol Use among Adult Urban Populations in Iran: A Knowledge, Attitude, and Practice Study. J Psychoactive Drugs [Internet]. 2019;51(3):290-7. Available from: https://doi.org/10.1080/02791072.2019.1578909

9. John-langba J. Alcohol, Drug Use, and Sexual-risk Behaviors among Adolescents in Four SubSaharan African Countries. Proc Annu Meet Progr Popul Assoc Am. 2003;5-8.

10. Atwoli L, Mungla PA, Ndung MN, Kinoti KC, Ogot EM. Prevalence of substance use among college students in Eldoret, western Kenya. BMC Psychiatry [Internet]. 2011;11(1):34. Available from: http://www.biomedcentral.com/1471-244X/11/34

11. El Mahi M. Substance use problem in Sudan: elephant in the room. BJPsych Int [Internet]. 2018 Nov 26;15(4):89-91. Available from: https://www.cambridge.org/core/product/identifier/S2056474017000332/type/journal_article

12. Osman $T$, Victor $C$, Abdulmoneim A, Mohammed $H$, Abdalla $F$, Ahmed A, et al. Epidemiology of Substance Use among University Students in Sudan. J Addict. 2016;2016:1-8.

13. Nadim AA, Rahim SIA. Clinical Aspects of Alcoholic Addiction in the Sudan 1st January 1979 - 31st December 1979. Br J Addict. 1984;79(4):449-50.

14. Omer AA, Hassan RME, Ali AY. Socio-demographic characteristics and types of illicit drugs used in Sudan, a Hayat rehabilitation center experience. Int J Emerg Ment Health. 2016;18(3):3-5.

15. Tesfaye G, Derese A, Hambisa MT. Substance Use and Associated Factors among University Students in Ethiopia: A Cross-Sectional Study. J Addict. 2014;2014:1-8.

16. National Institute on Drug Abuse [Internet]. 2017. Available from: https://www.drugabuse.gov/drugtopics/trends-statistics/costs-substance-abuse

17. Han B, Compton WM, Blanco C, Crane E, Lee J, Jones CM. Prescription opioid use, misuse, and use disorders in U.S. Adults: 2015 national survey on drug use and health. Ann Intern Med. 2017;167(5):293-301.

18. Bahorik AL, Satre DD, Kline-Simon AH, Weisner CM CC. Alcohol, Cannabis, and Opioid Use Disorders, and Disease Burden in an Integrated Healthcare System. HHS Public Access. 2018;11(1):3-9.

19. Chawla S. World drug report 2011. UN office on drugs and crime (UNODC); 2011.

20. Prakash O, Prakash Giri O, Kumar Mishra A, Kumar S, Kulhara P. Knowledge and attitude of Indian adolescents towards addiction: Findings from an exploratory survey. J Ment Heal Hum Behav JMHHB [Internet]. 2009;14(2):74-9. Available from: http://www.ipsnz.org/original1-1.pdf

21. Cape G, Hannah A, Sellman D. A longitudinal evaluation of medical student knowledge, skills and attitudes to alcohol and drugs. Addiction [Internet]. 2006 Jun;101(6):841-9. Available from: https://onlinelibrary.wiley.com/doi/10.1111/j.1360-0443.2006.01476.x

\section{Supplementary Files}

This is a list of supplementary files associated with this preprint. Click to download. 
- Appnedix1.docx

Page 20/20 